\title{
Supramolecular nanotube-based fiber mats by self-assembly of a tailored amphiphilic low molecular weight hydrogelator $\dagger$
}

\author{
Andreas Bernet, Marina Behr and Hans-Werner Schmidt* \\ Received 31st May 2010, Accepted 12th October 2010 \\ DOI: 10.1039/c0sm00456a
}

The amide-group containing amphiphile 4- $N$-octanoyl-aminobenzoic acid sodium salt is able to thermoreversibly form supramolecular hydrogels in aqueous solutions of alkanine sodium salts. The supramolecular assemblies can be transferred without destruction by a mold-casting/drying process into self-supporting macroscopic supramolecular nanofiber mats. These mats are thermally and mechanically stable, resistant to a large variety of organic solvents and therefore interesting for potential applications such as templating of inorganic materials and filtration. The nanotubular multiwalled morphology of the underlying supramolecular assemblies was revealed using field-emission scanning electron microscopy (FE-SEM), transmission electron microscopy (TEM), X-ray scattering (XRD) and Fourier-Transform infrared spectroscopy (FT-IR).

\section{Introduction}

Fibers with sub-micron diameters, so-called nanofibers, have gained a lot of attention in material science. ${ }^{1}$ Their increased aspect ratio and high surface area make nanofiber-based materials very promising for a broad spectrum of applications such as templating of inorganic materials, ${ }^{2}$ textile applications, ${ }^{3}$ filtration ${ }^{4}$ and catalysis. ${ }^{5}$ Furthermore, nanofibers can be used in medical applications, for example as matrices for tissue engineering, ${ }^{6}$ wound healing, ${ }^{7}$ and for transport and release of drugs. ${ }^{8}$

For the preparation of nanofibers, "top-down" and "bottomup" approaches are known. Technically applied "top-down" methods include melt blow processes, ${ }^{9}$ centrifugal spinning ${ }^{10}$ and electrospinning. ${ }^{11}$ Nanofibers prepared by "bottom-up" approaches such as molecular self-assembly ${ }^{\mathbf{1 2}}$ are in general not self-supporting and therefore require stabilizing scaffold structures to be manageable and applicable. ${ }^{13}$

Here we present a straightforward and reliable method based on self-assembly of a tailored low-molecular weight amphiphile enabling the preparation of stable, free-standing nanofibrillar fiber mats of macroscopic dimensions.

\section{Results and discussion}

\section{Thermoreversible hydrogel formation}

Out of a series of amphiphilic $\mathrm{N}$-amidated 4-aminobenzoic acid sodium salts, we found that a few are able to form stable hydrogels. The underlying structural motif of this class of amphiphiles includes, in addition to the polar headgroup and the hydrophobic tail, an amide linkage next to an aromatic moiety. Eleven derivatives of $\mathrm{N}$-amidated 3- and 4-aminobenzoic acids

Macromolecular Chemistry I, Bayreuther Institut für Makromolekülforschung (BIMF), Bayreuther Zentrum für Kolloide und Grenzfächen (BZKG), University of Bayreuth, D-95440 Bayreuth, Germany. E-mail: hans-werner.schmidt@uni-bayreuth.de; Fax: +49 (0) 921 553206; Tel: +49 (0)921553200

$\uparrow$ Electronic supplementary information (ESI) available: ${ }^{1} \mathrm{H}$ NMR spectrum of 1 in DMSO- $\mathrm{d}_{6}$ and a typical BET measurement of a nanofiber mat of $\mathbf{1 N a}$. See DOI: $10.1039 / \mathrm{c} 0 \mathrm{sm} 00456 \mathrm{a}$ with linear alkyl chains ranging between 3 and 13 methylene units were synthesized and tested with respect to their gelation behavior in basic aqueous media. Within the investigated series of compounds, especially the 4-(octanoylamino) benzoic acid sodium salt (1Na) showed exceptional hydrogel formation exclusively in aqueous solutions of alkaline sodium salts like sodium hydroxide, sodium hydrogen carbonate and sodium carbonate (Fig. 1). For example, mixing of the free acid 1 with aqueous sodium hydroxide solution $\left(40 \mathrm{~g} \mathrm{~L}^{-1}\right.$ of $\left.\mathrm{NaOH}\right)$ at elevated temperatures results in a homogeneous solution of the corresponding sodium salt $\mathbf{1 N a}$. Upon cooling, self-assembly via several hierarchical levels takes place, resulting in a threedimensional fibrillar network structure which subsequently gels the solvent. Due to the non-covalent intermolecular interactions,

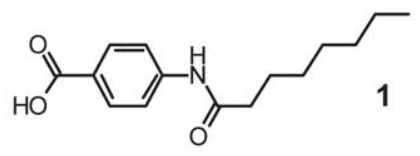

$\lceil$ aqueous base

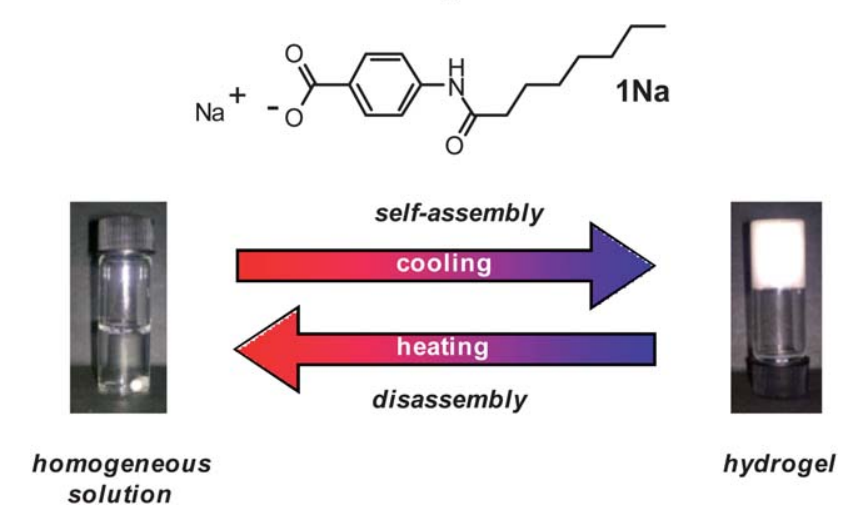

Fig. 1 Chemical structure of 4-(octanoylamino) benzoic acid 1 and the corresponding sodium salt $1 \mathrm{Na}$. Optical images of the sol state at $85^{\circ} \mathrm{C}$ (left) and the gel state at room temperature (right) of $1 \mathbf{N a}$ in aqueous $\mathrm{NaOH}$ solution (initial concentration of 1: $10 \mathrm{~g} \mathrm{~L}^{-1}, 40 \mathrm{~g} \mathrm{~L}^{-1}$ of $\mathrm{NaOH}$ ). 
the hydrogels are thermoreversible and can be transformed from the gel state at room temperature to the sol state by heating and vice versa. The system has a gel-sol transition temperature $\left(T_{\text {gel }}\right)$ which depends on the gelator concentration.

The influence of the gelator concentration on $T_{\text {gel }}$ shows a typical behavior for supramolecular hydrogels (Fig. 2). At very low concentrations, the amount of gelator is too low to provide a stable three-dimensional network, so no macroscopic gel is formed. When the critical gelation concentration is reached, this results in the formation of a gel sample with a defined $T_{\text {gel }}$. Upon further increase of the gelator concentration, $T_{\text {gel }}$ shifts to higher values, as the supramolecular network density increases. Finally, a plateau of $T_{\text {gel }}$ is reached.

Not only the gelator concentration but also the type and content of salt in the aqueous solutions used for hydrogel preparation has a significant influence on the gel formation (Table 1). When we investigated the behavior of $\mathbf{1 N a}$ in different aqueous solutions of alkaline sodium salts, we found that a certain amount of sodium salt is necessary for hydrogel formation. Furthermore, the time for complete gelation of the sample decreases with increasing salt content from days to a few minutes. This indicates a pronounced "salt effect" during the gel formation and can be utilized to perform salt-induced supramolecular hydrogel formation (Fig. 3). For example, an aqueous mixture of $20 \mathrm{~g} \mathrm{~L}^{-1}$ of $\mathbf{1}$ in an aqueous sodium hydroxide solution $\left(5 \mathrm{~g} \mathrm{~L}^{-1}\right.$ of $\left.\mathrm{NaOH}\right)$ appears as a clear fluid solution after heating to $85{ }^{\circ} \mathrm{C}$ and cooling to room temperature and is stable for several days without showing any gel formation. If we now increase the sodium salt content, for example by the addition of saturated sodium hydrogen carbonate solution, the whole sample is transformed into a opaque hydrogel within seconds to few minutes, depending on the type and amount of sodium salt.

\section{Preparation of nanofiber mats}

We discovered that the fibrillar assemblies within the gel samples are stable and it is possible to remove the solvent without

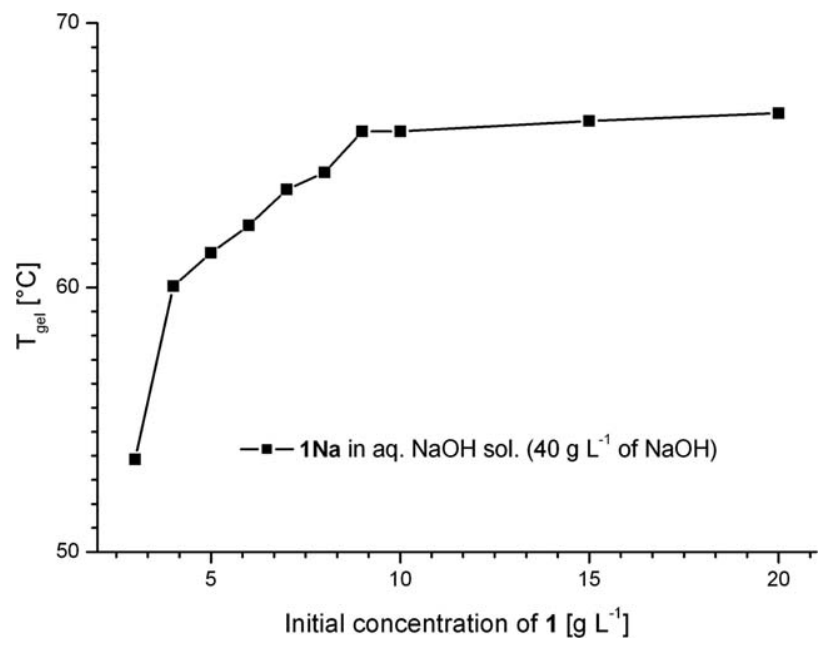

Fig. 2 Influence of the initial concentration of $\mathbf{1}$ on the gel-sol transition temperature $T_{\text {gel }}$ of the corresponding hydrogel (solvent: aqueous $\mathrm{NaOH}$ solution, $40 \mathrm{~g} \mathrm{~L}^{-1}$ of $\mathrm{NaOH}$ ). Note: the free acid $\mathbf{1}$ is transformed in situ into the gelator $1 \mathrm{Na}$ due to the alkaline aqueous media.
Table 1 Influence of the sodium salt concentration on the gelation behavior of $1 \mathrm{Na}$ in aqueous solutions. Initial concentration of $1=5 \mathrm{~g}$ $\mathrm{L}^{-1}$. Note: the free acid $\mathbf{1}$ is transformed in situ into the gelator $\mathbf{1 N a}$ due to the alkaline aqueous media

\begin{tabular}{|c|c|c|c|c|c|}
\hline \multirow{2}{*}{\multicolumn{2}{|c|}{$\frac{\text { Aq. } \mathrm{Na}_{2} \mathrm{CO}_{3} \text { sol. }^{a}}{c \text { (salt) } / \mathrm{g} \mathrm{L}^{-1}}$}} & \multirow{2}{*}{\multicolumn{2}{|c|}{$\frac{\text { Aq. } \mathrm{NaHCO}_{3} \text { sol. }}{c \text { (salt) } / \mathrm{g} \mathrm{L}^{-1}}$}} & \multirow{2}{*}{\multicolumn{2}{|c|}{$-\frac{\text { Aq. } \mathrm{NaOH} \text { sol. }}{c \text { (salt) } / \mathrm{g} \mathrm{L}^{-1}}$}} \\
\hline & & & & & \\
\hline 50 & $\mathrm{~s}$ & 10 & $\mathrm{~s}$ & 0.5 & $\mathrm{~s}$ \\
\hline 100 & $\mathrm{~g}(1 \mathrm{~d})$ & 20 & $\mathrm{~s}$ & 1 & $\mathrm{~s}$ \\
\hline 150 & $\mathrm{~g}(15 \mathrm{~min})$ & 30 & $\mathrm{~s}$ & 5 & $\mathrm{~s}$ \\
\hline 200 & $\mathrm{~g}(10 \mathrm{~min})$ & 40 & $\mathrm{~g}(1 \mathrm{~d})$ & 10 & $\mathrm{~s}$ \\
\hline 300 & $\mathrm{~g}(10 \mathrm{~min})$ & 50 & $\mathrm{~g}(35 \mathrm{~min})$ & 15 & $\mathrm{~s}$ \\
\hline 400 & $\mathrm{p}$ & 60 & $\mathrm{~g}(20 \mathrm{~min})$ & 20 & $\mathrm{~g}(35 \mathrm{~min})$ \\
\hline 500 & $\mathrm{p}$ & 70 & $\mathrm{~g}(15 \mathrm{~min})$ & 25 & $\mathrm{~g}(20 \mathrm{~min})$ \\
\hline 600 & $\mathrm{p}$ & 80 & $\mathrm{~g}(15 \mathrm{~min})$ & 30 & $\mathrm{~g}(15 \mathrm{~min})$ \\
\hline 700 & $\mathrm{i}$ & 90 & $\mathrm{~g}(10 \mathrm{~min})$ & 35 & $\mathrm{~g}(15 \mathrm{~min})$ \\
\hline 800 & $\mathrm{i}$ & 100 & $\mathrm{~g}(10 \mathrm{~min})$ & 40 & $\mathrm{~g}(10 \mathrm{~min})$ \\
\hline
\end{tabular}

${ }^{a} \mathrm{Na}_{2} \mathrm{CO}_{3} \times 10 \mathrm{H}_{2} \mathrm{O}$ was used for the preparation of the solution. Note: $\mathrm{s}$ : clear solution after heating and cooling; g: homogeneous gel (time for gelation); p: only partially soluble at $90{ }^{\circ} \mathrm{C}$; and i: insoluble at $90{ }^{\circ} \mathrm{C}$.

destroying the network structure, resulting in free-standing and self-supporting nanofibrillar fiber mats. The adopted preparation steps are illustrated in Fig. 4. A mixture comprising $10 \mathrm{~g} \mathrm{~L}^{-1}$ of $\mathbf{1}$ and aqueous sodium hydroxide solution $\left(40 \mathrm{~g} \mathrm{~L}^{-1}\right.$ of $\left.\mathrm{NaOH}\right)$ is heated under stirring to $85^{\circ} \mathrm{C}$ yielding a homogeneous solution. This hot solution is poured into a Teflon ${ }^{\circledR}$ mold (diameter: $65 \mathrm{~mm}$, filling height: $5-10 \mathrm{~mm}$ ). The mold is covered with a glass plate in order to prevent evaporation of the solvent. During the cooling process, gelation occurs very rapidly. After ten minutes, the entire sample is sufficiently stable to be completely removed and transferred on top of a plaster disc covered with a thin layer of paper pulp. A second plaster/paper pulp disc was put on top, resulting in a sandwich-type setup. Gentle compression is applied and the sodium hydroxide solution is almost completely removed by capillary forces.

We determined by elemental analysis in combination with thermogravimetric analysis that this process removes $98 \%$ of the sodium hydroxide solution. The sample is mechanically stable enough to be lifted off without destruction. To remove traces of

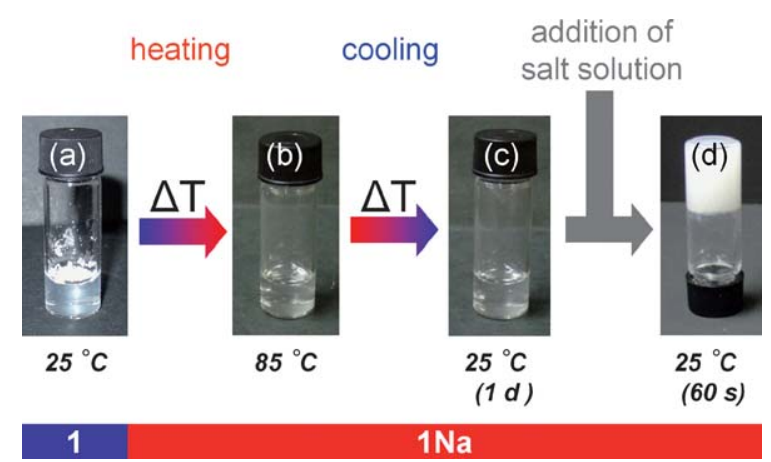

Fig. 3 Salt-induced hydrogel formation of 1 Na. (a) Suspension of $20 \mathrm{~g}$ $\mathrm{L}^{-1}$ of 1 in aqueous $\mathrm{NaOH}$ solution $\left(5 \mathrm{~g} \mathrm{~L}^{-1}\right.$ of $\left.\mathrm{NaOH}\right)$ before heating; (b) homogeneous sample at $85^{\circ} \mathrm{C}$; (c) homogeneous solution (stored for $24 \mathrm{~h}$ at room temperature); (d) hydrogel sample $1 \mathrm{~min}$ after addition of saturated $\mathrm{NaHCO}_{3}$ solution $\left(100 \mathrm{~g} \mathrm{~L}^{-1}\right.$ of $\left.\mathrm{NaHCO}_{3}\right)$ at room temperature. 


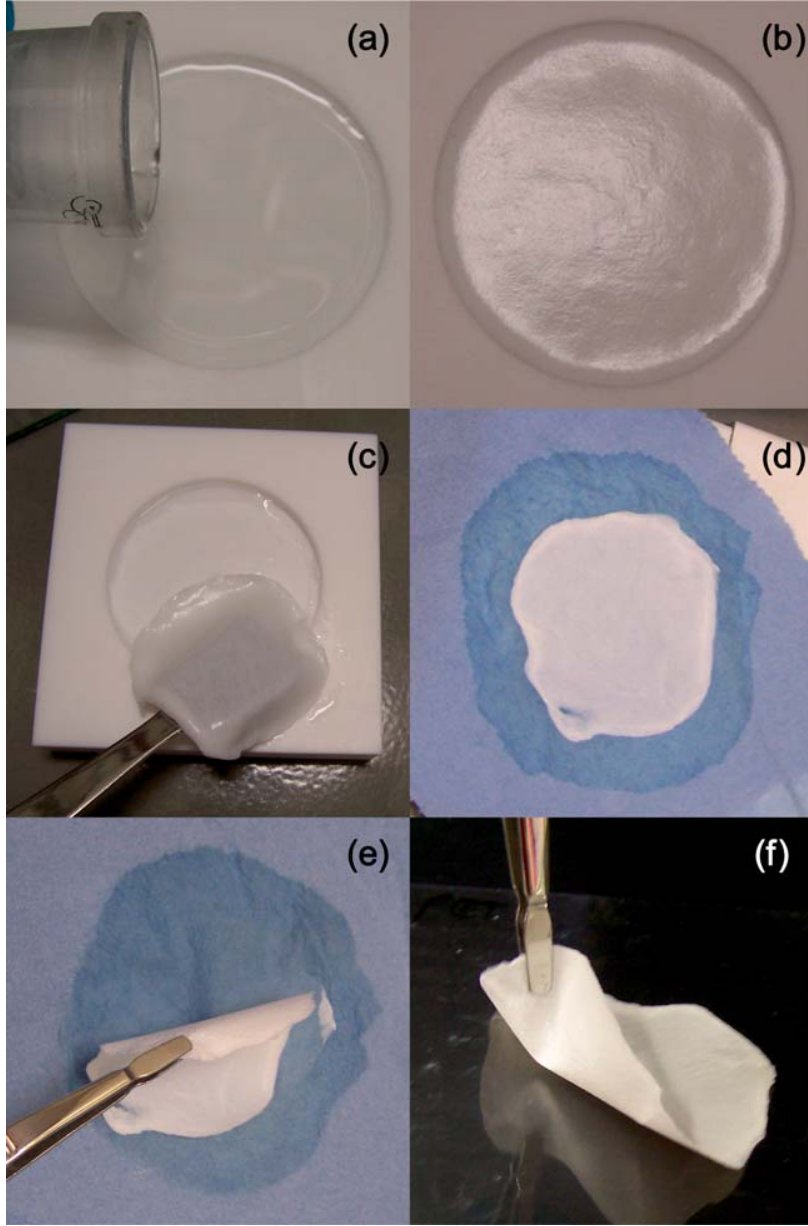

Fig. 4 Preparation of supramolecular nanofibrillar fiber mats: (a) moldcasting of the solution of the sodium salt $1 \mathrm{Na}$ at $85^{\circ} \mathrm{C}$; (b) self-assembly induces gelation during cooling; (c) removal of the gel sample from mold; (d) removal of the solvent by compression between paper pulp and plaster slides (only one half of the sandwich-type setup is shown); (e) lifting off the sample; and (f) supramolecular fiber mat after oven drying.

water, the sample was air-dried for $30 \mathrm{~min}$ at $80^{\circ} \mathrm{C}$. The thickness of the resulting samples directly depends on the initial filling height of the mold. In the case of $5 \mathrm{~mm}$ height of the gel sample we obtained a dried fiber mat with a thickness of $0.06 \mathrm{~mm}$. A filling height of $10 \mathrm{~mm}$ resulted in a fiber mat with a thickness of $0.12 \mathrm{~mm}$. During the drying step under compression the twodimensional shape is maintained and only the thickness is reduced. The specific surface area of the fiber mats was investigated by Brunauer-Emmett-Teller (BET) experiments. A surface area of about $26 \mathrm{~m}^{2} \mathrm{~g}^{-1}$ was determined. This demonstrates the porous structure of the samples.

\section{Mechanical stability of nanofiber mats}

In order to get a first information on the mechanical stability of the nanotubular assemblies, we prepared supramolecular nanofiber stripes with defined dimensions and carried out some stressstrain experiments (Fig. 5). The results show that the nanofiber stripes are mechanically quite robust, with an elongation at break of approx. $1 \%$ at a stress of $0.53 \mathrm{MPa}$.

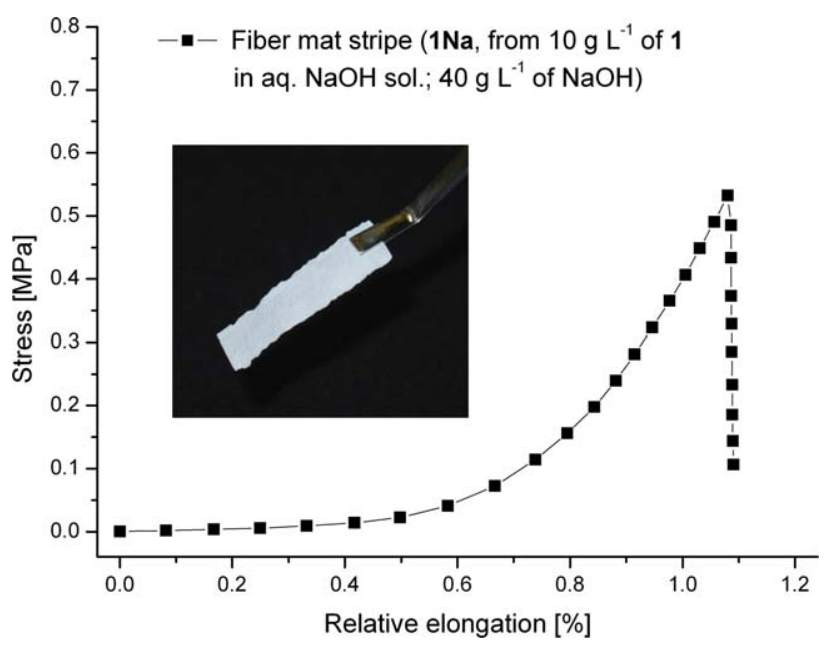

Fig. 5 Stress-elongation diagram of supramolecular nanofiber stripe (1Na, prepared from $10 \mathrm{~g} \mathrm{~L}^{-1}$ of $\mathbf{1}$ in aqueous $\mathrm{NaOH}$ solution, $40 \mathrm{~g} \mathrm{~L}^{-1}$ of $\mathrm{NaOH})$. Inset: optical image of nanofiber stripe.

\section{Solvent resistance of nanofiber mats}

The stability against solvents of the fiber mats was tested by immersing small samples (diameter: $10 \mathrm{~mm}$, thickness: $0.06 \mathrm{~mm}$ ) in different solvents at room temperature. Due to their salt-like nature, the fiber mats keep their integrity in several organic solvents including dichloromethane, chloroform, tetrahydrofurane, ethyl acetate, acetone, butanol, isopropyl alcohol and ethanol. In aqueous media, the stability depends on salt content and $\mathrm{pH}$ value. Under acidic conditions or at low salt concentration, disintegration takes place. At higher $\mathrm{pH}$ values and higher salt content, the fiber mat samples are macroscopically stable for weeks. Furthermore, heating the dried fiber mats in aqueous sodium hydroxide solution $\left(40 \mathrm{~g} \mathrm{~L}^{-1}\right.$ of $\left.\mathrm{NaOH}\right)$ followed by cooling to room temperature leads back to hydrogels with the initial macroscopic properties.

\section{Thermal stability of nanofiber mats}

In literature, other amphiphilic systems are reported which are able to form tubular morphologies via self-assembly in aqueous media. ${ }^{14}$ Nanotubular structures were found for example with phospholipids, glycolipids, peptidic amphiphiles and bolaamphiphiles, all of them featuring relatively long apolar chains. The here presented tubular morphologies based on the anionic amphiphile 1Na have the advantage of a substantial enhanced thermal stability. This increased thermostability is caused by the combination of a shorter alkyl chain, strong intermolecular interactions by hydrogen-bonds and by the salt-type headgroup. Thermogravimetric analysis (Fig. 6) revealed that the fiber mats of $1 \mathrm{Na}$ contain only small amounts of water (about $2 \mathrm{wt} \%$ ). The onset of weight loss is around $310{ }^{\circ} \mathrm{C}$. The corresponding acid $\mathbf{1}$ contains practically no water and is less stable. The onset of weight loss occurs already around $250{ }^{\circ} \mathrm{C}$. Annealing experiments of the fiber mats were carried out in air at $155^{\circ} \mathrm{C}$. SEM investigations of the annealed samples demonstrated that the tubular morphology of the fibers is unchanged. 


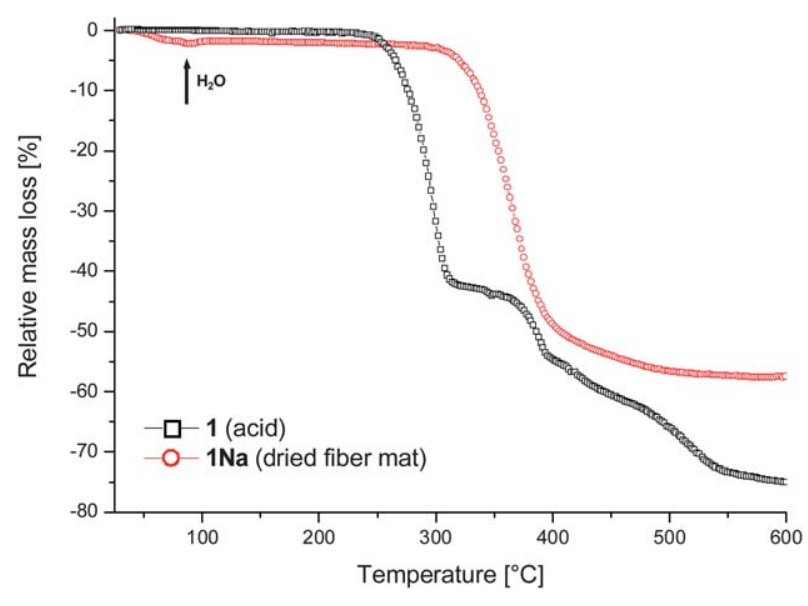

Fig. 6 TGA curves (nitrogen atmosphere, heating rate $10{ }^{\circ} \mathrm{C} \mathrm{min}^{-1}$ ) of acid $\mathbf{1}$ and the corresponding sodium salt $\mathbf{1 N a}$ as fiber mat (prepared from $10 \mathrm{~g} \mathrm{~L}^{-1}$ of 1 in aqueous $\mathrm{NaOH}$ solution, $40 \mathrm{~g} \mathrm{~L}^{-1}$ of $\left.\mathrm{NaOH}\right)$.

\section{Morphology of nanofiber mats}

Scanning electron microscopy images of the supramolecular fiber mats are shown in Fig. 7. Image (a) shows an edge view of a fractured sample, proving that an uniform fibrillar morphology exists throughout the whole interior of the sample. Image (b) shows the top view of a sample revealing the fibrillar structure with fiber lengths of several tens of micrometres. An image of a cryo-fractured sample (c) shows that the nanofibrillar fiber mats consist of uniform fibers with a well-defined circular crosssection and indicates a hollow interior of the nanofibers. In all cases, we did not observe residual salt on the fiber surfaces. In order to finally prove the nanotubular morphology, TEM experiments of pieces of single fibers were carried out. Fig. 7(d) clearly shows the morphology of a hollow nanofiber. The nanofibers are very uniform with respect to the inner and outer diameter. A statistical evaluation of about 50 individual fiber pieces resulted in an average outer diameter of $88 \pm 14 \mathrm{~nm}$ and an average inner diameter of $22 \pm 3 \mathrm{~nm}$.

\section{Structural investigations of the nanofibers}

In order to get more information on molecular arrangement of $1 \mathrm{Na}$ in the supramolecular assemblies, we carried out XRD and FT-IR experiments. In Fig. 8 the XRD pattern of a hydrogel sample prepared from $10 \mathrm{~g} \mathrm{~L}^{-1}$ of $\mathbf{1}$ in aqueous sodium hydroxide solution $\left(40 \mathrm{~g} \mathrm{~L}^{-1}\right.$ of $\left.\mathrm{NaOH}\right)$ is shown. A sharp peak at $2.36^{\circ}(2 \theta)$ corresponding to a $d$-spacing of $3.74 \mathrm{~nm}$ is observed. Additionally, a weak peak (indicated by an arrow) at $7.12^{\circ}(2 \theta)$ can be found. Both peaks can be retrieved when examining a dried fiber mat, thus indicating that the structure is retained during the drying process. The XRD analysis of the dried fiber mat yields a stronger diffraction pattern due to much higher concentration of scattering material in the Mark-tube compared to the gel sample. As the $2 \theta$ values of the peak series behave like $1: 2: 3: 4: 5$, this clearly indicates a highly ordered multilayer superstructure composed of bilayers.

Together with additional WAXS experiments of dried fiber mats of 1Na, an indexing of the Bragg peaks is possible and proposes an orthorhombic elementary cell with $a=3.6 \mathrm{~nm}$,

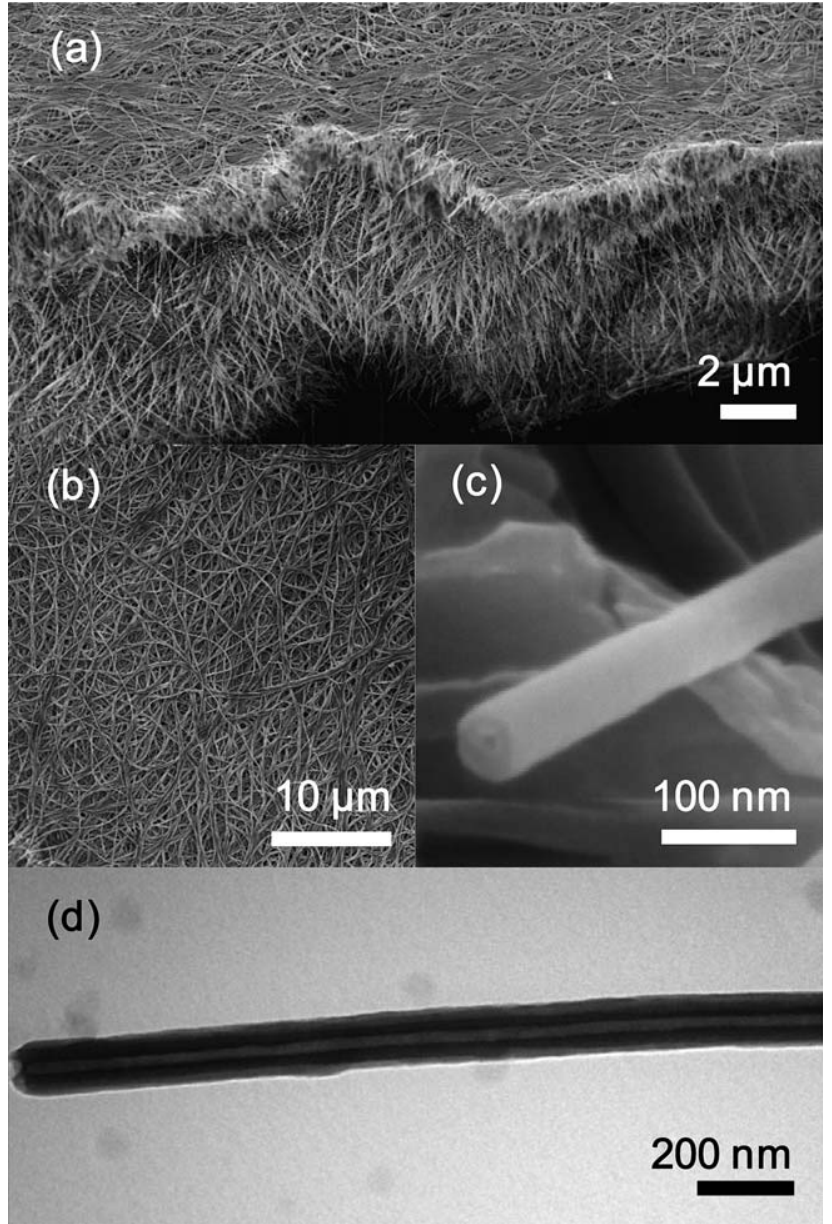

Fig. 7 SEM images $(\mathrm{a}-\mathrm{c})$ of supramolecular fiber mats of $\mathbf{1 N a}$ prepared from $10 \mathrm{~g} \mathrm{~L}^{-1}$ of 1 in aqueous $\mathrm{NaOH}$ solution $\left(40 \mathrm{~g} \mathrm{~L}^{-1}\right.$ of $\left.\mathrm{NaOH}\right)$ (superposition of two images with different focus); (a) edge view and (b) top view of the fractured nanofibrillar fiber mat; (c) cryo-fractured sample showing the circular cross-section and the hollow interior of a nanofiber; and (d) TEM image of a piece of a single nanotubular fiber.

$b=1.2 \mathrm{~nm}$ and $c=0.5 \mathrm{~nm}$. Considering the molecular dimensions of $1 \mathrm{Na}$, we assume a multi-walled tube structure for the nanofibers with the walls consisting of bilayers of the amphiphile. Considering the results from the TEM experiments on inner and outer diameter of the nanotubes, the estimated average number of bilayers in a nanotube is around 9 to 10 .

The tendency of $\mathbf{1 N a}$ to form bilayer assemblies is also expressed by the fact that platelet crystals slowly precipitate from solutions of $1 \mathrm{Na}$ in aqueous sodium hydroxide solution under certain conditions. If a mixture of $\mathbf{1}$ and aqueous sodium hydroxide solution (10-20 $\mathrm{g} \mathrm{L}^{-1}$ of $1,5 \mathrm{~g} \mathrm{~L}^{-1}$ of $\mathrm{NaOH}$ ) is heated to $85{ }^{\circ} \mathrm{C}$ and cooled down to room temperature subsequently, spherical micelles of $1 \mathrm{Na}$ are initially formed and can be visualized by cryo-TEM methods (Fig. 9(a)). After standing at room temperature for several weeks, platelet crystals of $1 \mathrm{Na}$ can be recognized (Fig. 9(b)). By cryo-TEM experiments and in situ small-angle electron diffraction (SAED) of these platelets (Fig. 9(c) and (d)), we could prove that these macroscopic "flat" platelet crystals of $\mathbf{1 N a}$ consist of stacks of flat bilayers.

Furthermore, SAED experiments of such aggregates (Fig. 9(d)) indicate an orthogonal arrangement of the 

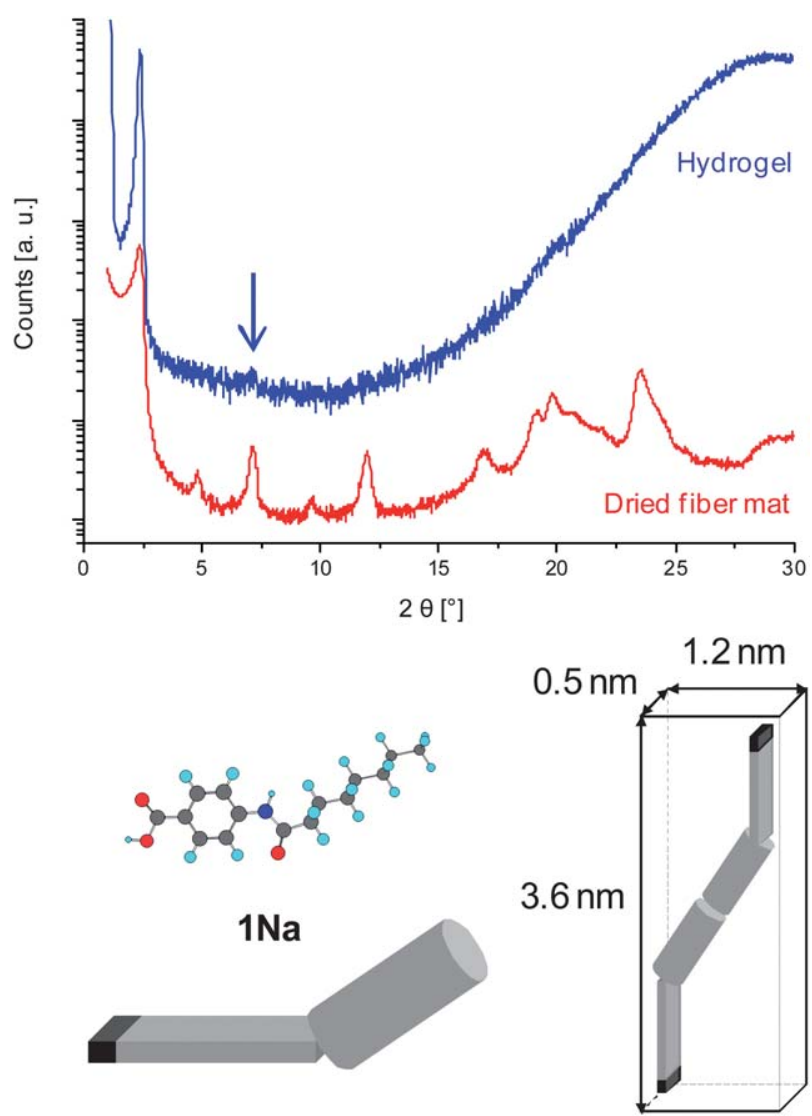

Fig. 8 Top: XRD patterns of $\mathbf{1 N a}$ in a hydrogel and a dried fiber mat (prepared from $10 \mathrm{~g} \mathrm{~L}^{-1}$ of 1 in aqueous $\mathrm{NaOH}$ solution, $40 \mathrm{~g} \mathrm{~L}^{-1}$ of $\mathrm{NaOH})$. Note: the hydrogel curve was magnified for more clarity. The arrow indicates a weak second Bragg peak. Bottom: molecular model of $1 \mathrm{Na}$ and the proposed arrangement of two molecules within the unit cell determined by XRD indexing methods.

amphiphiles within the stacked bilayers. The corresponding $d$-spacings were calculated as 1.2 and $0.5 \mathrm{~nm}$, which fit very well with the proposed values from the XRD indexing results (compare Fig. 8). Additionally, the proposed molecular arrangement of the amphiphile $\mathbf{1} \mathbf{N a}$ is in good agreement with reported results where the bulk structure of several $N$-alkanoyl $p$-aminobenzoic acids was investigated in detail. ${ }^{15}$ These amphiphiles form dimers via the carboxylic moieties. In addition, the amide groups interact via hydrogen bonds, thus enforcing a lateral stabilization of the supramolecular structure.

The difference between a flat bilayer stacking and a furled multi-wall nanotubular arrangement can be visualized using FT-IR methods. Within flat bilayers, all amphiphiles are spatially equal, resulting in only one type of amide group. The acid 1 exhibits a sharp peak at $3318 \mathrm{~cm}^{-1}(\nu(\mathrm{N}-\mathrm{H}))$ which indicates a single species of hydrogen-bonded aromatic amide groups (Fig. 10). The platelet crystals of $1 \mathrm{Na}$ also show only one sharp peak at $3322 \mathrm{~cm}^{-1}$. In contrary, the FT-IR spectrum of a dried fiber mat shows two broadened and overlapping peaks at $3324 \mathrm{~cm}^{-1}$ and $3280 \mathrm{~cm}^{-1}$. We propose that the bending of the bilayers in the nanotubular assemblies results in a kind of differentiation into inner (compression) and outer (expansion) surface of the bilayer, being expressed in two amide peaks. Furthermore, the radius of curvature changes from the inside to

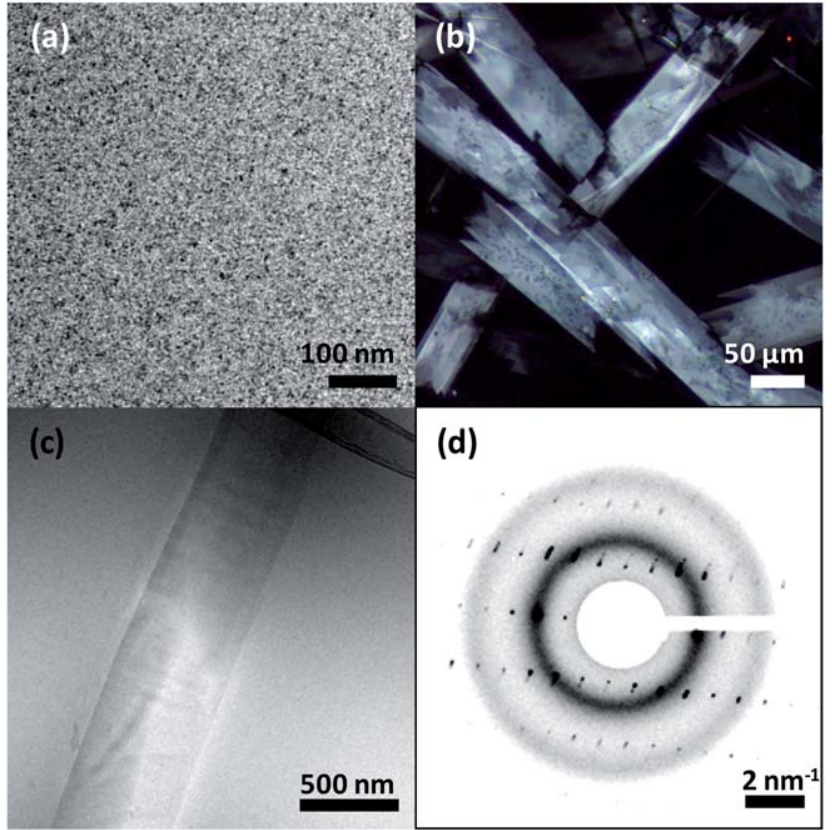

Fig. 9 Supramolecular assemblies of $\mathbf{1} \mathrm{Na}$ in aqueous $\mathrm{NaOH}$ solution (10 $\mathrm{g} \mathrm{L}^{-1}$ of $1,5 \mathrm{~g} \mathrm{~L}^{-1}$ of $\left.\mathrm{NaOH}\right)$. (a) Cryo-TEM image of a micellar solution of $1 \mathrm{Na}$ after $1 \mathrm{~d}$ at $25^{\circ} \mathrm{C}$ ); (b) polarized optical microscope image of platelet crystals of $1 \mathrm{Na}$ after standing at $25^{\circ} \mathrm{C}$ for several weeks; (c) cryo-TEM image and (d) small-angle dark-field electron diffraction image of a platelet crystal of $\mathbf{1 N a}$.

the outside of the nanotube, thus leading to slightly different environments of the amphiphiles and consequently resulting in broadening of the peaks.

\section{Proposed gel formation mechanism}

Summarizing all the experimental results, the self-assembly and hydrogel formation behavior of $\mathbf{1 N a}$ can be explained as follows

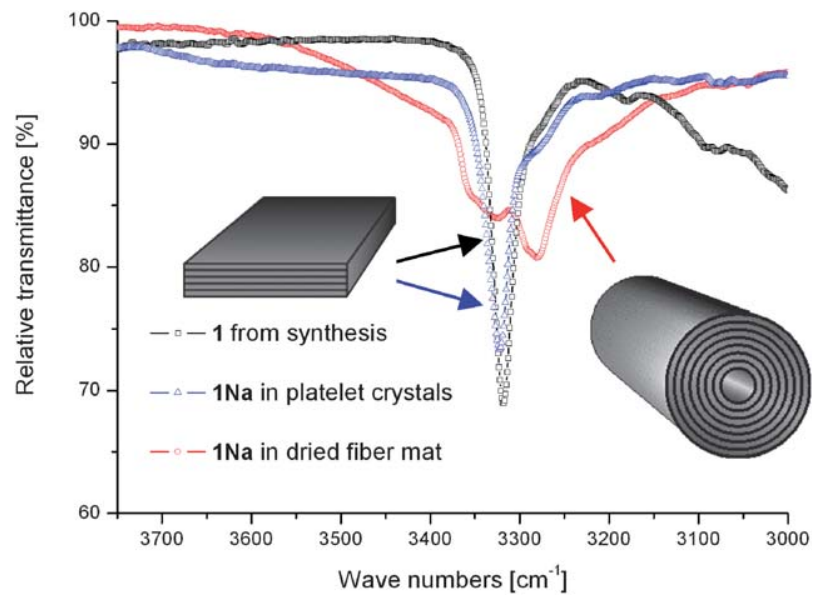

Fig. 10 FT-IR spectra of acid $\mathbf{1}$ and the corresponding sodium salt $\mathbf{1 N a}$ as crystallized platelets (prepared from $10 \mathrm{~g} \mathrm{~L}^{-1}$ of $\mathbf{1}$ in aqueous $\mathrm{NaOH}$ solution, $5 \mathrm{~g} \mathrm{~L}^{-1}$ of $\mathrm{NaOH}$ ) and as dried fiber mat (prepared from $10 \mathrm{~g} \mathrm{~L}^{-1}$ of 1 in aqueous $\mathrm{NaOH}$ solution, $40 \mathrm{~g} \mathrm{~L}^{-1}$ of $\mathrm{NaOH}$ ). The inset illustrates the flat bilayer stack morphology of the acid $\mathbf{1}$ and of $\mathbf{1 N a}$ platelets and the proposed multi-walled morphology of the tubular nanofibers. 
(Fig. 11). In the first step, 1 is mixed with the aqueous solution of alkaline sodium salt. During heating the free acid $\mathbf{1}$ is transformed into the corresponding sodium carboxylate $\mathbf{1 N a}$. The following steps during cooling to room temperature depend on the amount of sodium salt in the initial solution. At a low sodium salt content, spherical micellar aggregates are formed which are stable for several days. If the amount of sodium salt is increased, i.e. by mixing with a saturated aqueous solution of sodium hydrogen carbonate, fast hydrogel formation takes place. Otherwise, the initial spherical micelles transform into ribbons and platelets consisting of multiple stacks of bilayers of $1 \mathrm{Na}$ within weeks. In contrary, if a higher sodium salt content is used to prepare the initial mixture, upon cooling the hot solution transforms very quickly into a supramolecular hydrogel consisting of multi-walled tubular nanofibers of 1Na. Interestingly, both of these gel formation procedures result in hydrogel samples featuring the same morphology and size of the supramolecular aggregates of $\mathbf{1 N a}$, and both hydrogels are fully thermoreversible.

The sensitivity of the hydrogel formation of $\mathbf{1 N a}$ towards the content of sodium salt can also be explained. As mentioned above, we found that $1 \mathrm{Na}$ is able to form stable hydrogels in aqueous solutions of sodium hydroxide, sodium hydrogen carbonate and sodium carbonate. In contrary, no gel formation was observed using the corresponding lithium or potassium salts. This "sodium effect" on the gel formation can be explained by a sodium ion aided "crosslinking" of micellar assemblies of the sodium carboxylate amphiphiles. As it has been demonstrated very recently experimentally and by molecular mechanics calculations,${ }^{16}$ only sodium ions seem to be able to "bridge" carboxylate headgroups between micellar structures, thus leading to hierarchical aggregation and the formation of superlattices. In our case, the bilayer units in the multi-walled nanotubes can be held together by this sodium-ion bridging interactions. This also explains why at a high sodium salt content, hydrogel formation takes place immediately, whereas at low content, isolated micellar aggregates can be found. Additionally, the high sodium salt content results in a "salting-out" Hofmeister effect, as hydrophobic intermolecular interactions are strengthened, thus also leading to enforced molecular aggregation. In summary, three main forces are guiding the molecular self-assembly of the carboxylate amphiphile $\mathbf{1 N a}$ : hydrophilic/hydrophobic interactions lead to the formation of spherical micelles. Intermolecular attraction by hydrogen bonding via the amide moieties results in the transformation of the micelles into less curved bilayer structures. Finally, bridging of the carboxylate-decorated bilayers by sodium ions yields stacked aggregates. In the case of lower sodium salt content, platelet crystals are formed very slowly. At higher sodium salt content, multi-walled nanotubes are formed, leading to the fast formation of a macroscopic hydrogel.

\section{Experimental details}

\section{General methods and materials}

All chemicals were used as received (Sigma-Aldrich) without further purification.

\section{Synthesis of 4-(octanoylamino) benzoic acid (1)}

$6.00 \mathrm{~g}$ of 4 -aminobenzoic acid $(43.7 \mathrm{mmol})$ were dissolved in $240 \mathrm{~mL}$ of acetone, $9.26 \mathrm{~g}$ of sodium carbonate $(87.4 \mathrm{mmol})$ were added and the mixture was stirred for several minutes. $6.75 \mathrm{~mL}$ of octanoyl chloride $(6.43 \mathrm{~g}, 43.7 \mathrm{mmol})$ were added slowly while cooling the mixture in a water bath. While stirring for about $4 \mathrm{~h}$ at ambient temperature, a white solid precipitated. After removal of the acetone by vacuum distillation the residual solid was elutriated with $400 \mathrm{~mL}$ of distilled water, and concentrated aqueous $\mathrm{HCl}$ was used to adjust the $\mathrm{pH}$ value of the suspension to approximately 3 . The mixture was then filtrated using a sintered funnel and the precipitate was washed with $500 \mathrm{~mL}$ of desalted water. The residue was dried in air flow in the sintered funnel for $30 \mathrm{~min}$, at $70{ }^{\circ} \mathrm{C}$ under reduced pressure (rotary evaporator) for 3 hours and at room temperature in high vacuum (0.1 mbar) overnight. A white powder was obtained. Yield: $8.66 \mathrm{~g}$ (32.9 mmol, $75 \%$ ). Mp $238.9{ }^{\circ} \mathrm{C} .{ }^{1} \mathrm{H}$ NMR (300 MHz, DMSO-d $\mathrm{d}_{6}$, б) $12.64(\mathrm{~s}, 1 \mathrm{H},-\mathrm{COOH}), 10.14(\mathrm{~s}, 1 \mathrm{H},-\mathrm{NH}), 7.86(\mathrm{~d}, J=8.8 \mathrm{~Hz}$, $2 \mathrm{H}, \mathrm{Ar}-\mathrm{H}), 7.69$ (d, $J=8.8 \mathrm{~Hz}, 2 \mathrm{H}, \mathrm{Ar}-\mathrm{H}), 2.33(\mathrm{t}, J=7.4 \mathrm{~Hz}$, $\left.2 \mathrm{H},-\mathrm{CO}-\mathrm{CH}_{2}-\right), 1.59\left(\mathrm{~m}, 2 \mathrm{H},-\mathrm{CH}_{2}-\right), 1.25\left(\mathrm{~m}, 8 \mathrm{H},-\left(\mathrm{CH}_{2}\right)_{4}-\right)$, $0.86\left(\mathrm{t}, J=6.5 \mathrm{~Hz}, 3 \mathrm{H},-\mathrm{CH}_{3}\right)$ ppm. EIMS $(\mathrm{m} / \mathrm{z}(\%)): 263(7)$ $\left[\mathrm{M}^{+}\right], 179$ (14), 137 (100), 120 (14), 57 (18), 43 (15), 41 (12).

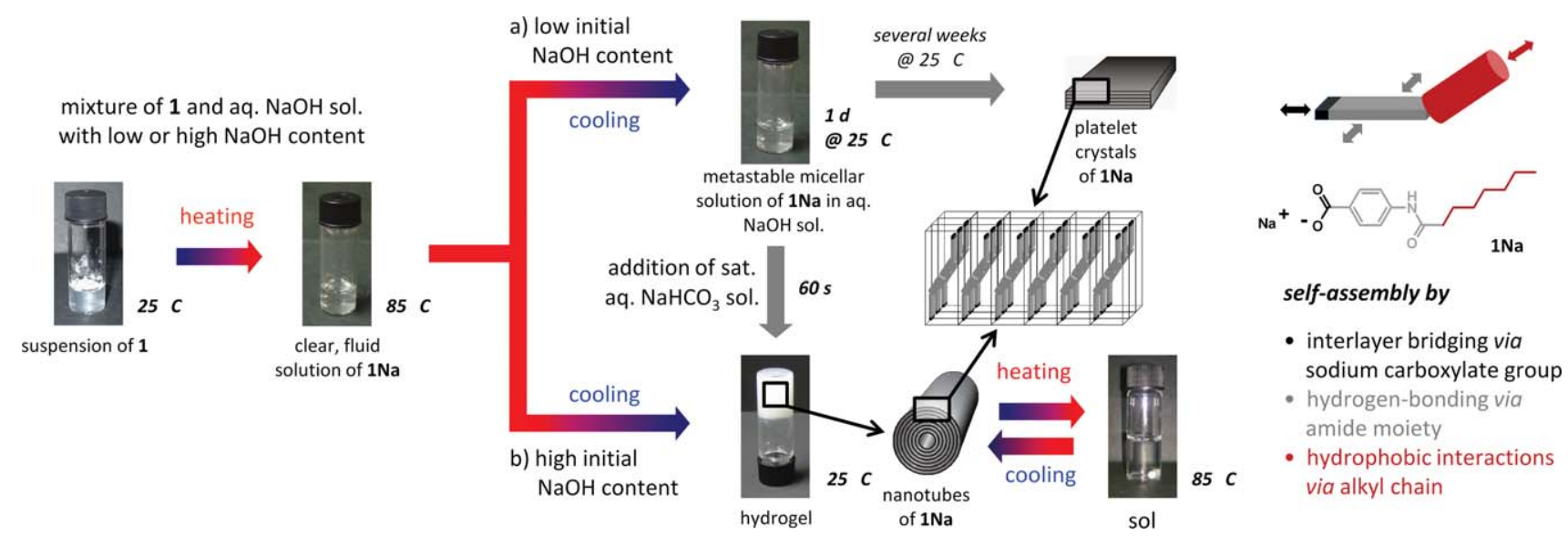

Fig. 11 Proposed salt-content dependent molecular self-assembly of $\mathbf{1 N a}$ in aqueous solutions of alkaline sodium salts and the resulting formation of a thermoreversible supramolecular hydrogel. 
Elemental anal. Calcd. for $\mathrm{C}_{15} \mathrm{H}_{21} \mathrm{NO}_{3}$ : $\mathrm{C}$ 68.42, $\mathrm{H}$ 8.04, $\mathrm{N}$ $5.32 \%$; found C 68.34, H 8.16, N 5.35\%.

\section{Melting point}

The melting point was measured using a MP90 Melting Point System (Mettler Toledo) at a heating rate of $10{ }^{\circ} \mathrm{C} \mathrm{min}^{-1}$.

\section{NMR experiments}

NMR experiments were carried out on a Bruker Avance AC 300 spectrometer at $298 \mathrm{~K}(300 \mathrm{MHz})$. The compounds were dissolved in DMSO- $\mathrm{d}_{6}$, which also acted as internal reference.

\section{Mass spectroscopy}

Mass spectra were recorded on a Finnigan MAT 8500 apparatus (EI, $70 \mathrm{eV}$ ) using direct injection mode.

\section{Elemental analysis}

Elemental analysis (C, H, N) was carried out with an EA 3000 instrument (HEKAtech). The amount of oxygen was calculated assuming that the difference between the measured amounts of carbon, hydrogen and nitrogen and $100 \%$ was the content of oxygen. The theoretical amount of all four elements was calculated using Isis Draw.

\section{Determination method for the gel-sol transition temperature $\left(T_{\text {gel }}\right)$}

The gel-sol transition temperature $T_{\text {gel }}$ was determined using the following "falling steel ball method". For the measurement, one $\mathrm{mL}$ of a hot gelator solution was filled into a screw cap vial (inner diameter: $12 \mathrm{~mm}$, filling height: $9 \mathrm{~mm}$ ), sealed and stored at room temperature overnight. A steel ball (diameter: $2 \mathrm{~mm}$, weight: $33 \mathrm{mg}$ ) was put on top of the gel, and the vial was heated slowly in an oil bath (heating rate: approx. $1^{\circ} \mathrm{C} \mathrm{min}^{-1}$ ). $T_{\text {gel }}$ was defined as the temperature at which the steel ball reached the bottom of the vial (average of two measurements). The temperature was measured in a reference vial filled with one $\mathrm{mL}$ of pure water.

\section{Determination of specific surface area}

BET measurements were performed by nitrogen physisorption at 77 K on a Quantachrome Autosorb 1 instrument. Approximately $100 \mathrm{mg}$ of the fiber mat were placed in a sample holder and degassed at $373 \mathrm{~K}$ for $24 \mathrm{~h}$. The value for the specific surface is the average of the results obtained from two independently prepared samples.

\section{Mechanical stability of nanofiber stripes}

Mechanical stability tests of supramolecular nanofiber stripes consisting of $1 \mathbf{N a}$ were carried out on an Instron Universaltester equipped with a $10 \mathrm{~N}$ load cell at a feed rate of $2 \mathrm{~mm} \mathrm{~min}^{-1}$. The nanofiber stripes were prepared by an adapted mold casting procedure using a silicone mold $(60 \times 10 \times 5 \mathrm{~mm})$ resulting in nanofiber stripes $(60 \times 10 \times 0.06 \mathrm{~mm})$. The effective stripe length for the measurements was $10 \mathrm{~mm}$. An initial concentration of $\mathbf{1}$ of
$10 \mathrm{~g} \mathrm{~L}^{-1}$ in aqueous sodium hydroxide solution $\left(40 \mathrm{~g} \mathrm{~L}^{-1}\right.$ of $\mathrm{NaOH}$ ) was used.

\section{Scanning electron microscopic study}

The nanotubular fiber assemblies obtained by the mold-casting and drying method were crushed using a spatula. Fragments of the fiber mat were mounted on a standard sample holder by conductive adhesion pad and examined with a Zeiss LEO 1530 (FE-SEM with Schottky-field-emission cathode, in-lens detector) using an accelerating voltage of $2-4 \mathrm{kV}$. The samples were sputtered with platinum prior to SEM imaging.

\section{Transmission electron microscopy}

The sample was prepared by placing the powdered fiber mat on top of a carbon-coated copper grid. Excess material was removed by gentle air flow. The sample was examined using a Zeiss CEM902 instrument at an accelerating voltage of $80 \mathrm{kV}$.

\section{(Cryo-)transmission electron microscopy}

A mixture of $10 \mathrm{mg}$ of $\mathbf{1}$ and $1.0 \mathrm{~mL}$ of aqueous sodium hydroxide solution $\left(5 \mathrm{~g} \mathrm{~L}^{-1}\right.$ of $\left.\mathrm{NaOH}\right)$ was stirred at room temperature until a homogeneous clear solution was formed. After standing at room temperature for one day, a drop of the solution was placed on a "lazy carbon" TEM grid. Excess of the solution was removed using a piece of filter paper. The sample was shock-frosted in liquid ethane and investigated using a Zeiss LEO EM922 Omega instrument.

\section{Optical polarizing microscopy}

A few drops of a sample of $\mathbf{1 N a}$ in aqueous sodium hydroxide solution containing macroscopic visible platelet crystals were placed on a glass microscopic slide and covered with a cover slide in order to prevent evaporation. Images were taken between crossed polarizers using a Nikon Diaphot 300 microscope equipped with a camera.

\section{Thermogravimetric analysis}

TGA measurements were performed with a NETZSCH simultaneous thermal analysis instrument STA 409 under nitrogen with a flow rate of $75 \mathrm{~cm}^{3} \mathrm{~min}^{-1}$. Approximately $10 \mathrm{mg}$ of the substance were put in an alumina crucible. The measurements were performed in the range of $25-600{ }^{\circ} \mathrm{C}$ at a heating rate of $10{ }^{\circ} \mathrm{C} \min ^{-1}$.

\section{XRD measurements}

XRD analysis of hydrogels and powdered fiber mats was performed on a Huber Guinier-Diffraktometer 6000, equipped with a Huber Quartz-Monochromator 611, a Cu-anode $\left(\mathrm{CuK}_{\alpha 1^{-}}\right.$ beam, $\lambda=154051 \mathrm{pm}$, X-ray generator from Seifert Company (Germany)), a Huber SMC 9000 stepping motor controller and a self-developed gate system, primary beam stopper and sample oven. XRD analysis of the hydrogel was carried out by filling pre-heated Mark tubes (outer diameter: $2 \mathrm{~mm}$, wall thickness: $0.01 \mathrm{~mm}$ ) with a hot solution of $\mathbf{1 N a}$ (from $10 \mathrm{~g} \mathrm{~L}^{-1}$ of $\mathbf{1}$ in aqueous sodium hydroxide solution, $40 \mathrm{~g} \mathrm{~L}^{-1}$ of $\mathrm{NaOH}$ ). The 
samples were sealed and stored at room temperature for $24 \mathrm{~h}$ prior to the XRD measurements. For WAXS experiments, a stack of four dried nanofiber stripes was attached to a metal sample holder using adhesive tape. XRD spectra were recorded on a Bruker $\mathrm{D} 8$ Advance $\mathrm{X}$-ray diffractometer $\left(\mathrm{CuK}_{\alpha 1}\right.$-beam, $\lambda=154051 \mathrm{pm}$, recording angle 5-80 $(2 \theta)$, angle increment $0.025^{\circ}(2 \theta)$, recording time $30 \mathrm{~s}$ per angle position). Peak indexing for the evaluation of the elemental cell type and dimensions was carried out using "Powder 3D" and "Crysfire" software.

\section{IR measurements}

IR spectra were recorded with a Perkin-Elmer Spectrum 100 FT-IR spectrometer in ATR mode. The samples were powdered prior to the measurements.

\section{Conclusions}

We presented a simple, reliable method for the preparation of supramolecular nanofiber mats which is based on the selfassembly process of a low-molecular weight sodium salt amphiphile. The fiber mats consist of multi-walled nanotubes exhibiting highly uniform inner and outer diameters. Due to the molecular structure of the underlying amphiphile, these fiber mats show a good thermal stability and are mechanically stable without the need of additional scaffold. The fiber mats are resistant to a variety of common organic solvents. This opens the door to further applications including templating of inorganic materials and filtration. Furthermore, it could be demonstrated that isolated micellar aggregates of the sodium carboxylate amphiphile can be transformed into hierarchical superstructures by changing the sodium salt content of the aqueous media, resulting in the formation of thermoreversible supramolecular hydrogels.

\section{Acknowledgements}

Funding by the German Research Foundation (DFG) is gratefully acknowledged. The synthesis of the amphiphiles and the characterization of the hydrogel systems were performed within the scope of SPP1259 "Intelligente Hydrogele". Preparation and characterization of nanofiber mats were carried out within SFB 840 "Von partikulären Nanosystemen zur Mesotechnologie" project B8. We would like to thank Dr W. Milius for the analysis of the XRD data, T. Lunkenbein for the BET measurements (Inorganic Chemistry I, Prof. J. Breu, University of Bayreuth), and C. Kunert and Dr M. Drechsler (BIMF/BZKG, University of Bayreuth) for conducting the TEM and cryo-TEM experiments.

\section{References}

1 Y. Dzenis, Science, 2004, 304, 1917; A. J. Epstein, Nat. Nanotechnol., 2007, 2, 354.

2 B. Ding and S. Shiratori, in New Nanotechnology Research, ed. J. P. Reese, Nova Science Hauppauge, NY, USA, 2006, ch. 5; M. Iusar and C. Sanchez, Chem. Mater., 2008, 20, 782.

3 M. Kumar, S. Subramanian and R. Geethamalini, Synth. Fibres, 2004, 33, 10; F.-L. Zhou, R.-H. Gong and I. Porat, Polym. Int., 2009, 58, 331.

4 K. Yoon, B. Hsiao and B. Chu, J. Mater. Chem., 2008, 18, 5326; R. S. Barhate and S. Ramakrishna, J. Membr. Sci., 2007, 296, 1; K. Schaefer, H. Thomas, P. Dalton and M. Moeller, in Materials Science 97: Multifunctional Barriers for Flexible Structure, Springer, Berlin, Germany, 2007, p. 125.

5 W. Ueda, M. Sadakane and H. Ogihara, Catal. Today, 2008, 132, 2.

6 L. A. Smith, X. Liu and P. X. Ma, Soft Matter, 2008, 4, 2144; A. Martins, R. L. Reis and N. M. Neves, Int. Mater. Rev., 2008, 53, 257.

7 Y. Zhang, C. T. Lim, S. Ramakrishna and Z.-M. Huang, J. Mater. Sci., 2005, 16, 933.

8 J. Venugopal, M. P. Prabhakaran, S. Low, A. T. Choon, G. Deepika, V. R. G. Dev and S. Ramakrishna, Curr. Pharm. Des., 2009, 15, 1799; N. Ashammakhi, I. Wimpenny, L. Nikkola and Y. Yang, J. Biomed. Nanotechnol., 2009, 5, 1.

9 F.-L. Zhou and R.-H. Gong, Polym. Int., 2008, 57, 837; J. Srinivasan and S. Kathirvelu, Synth. Fibres, 2006, 35, 27.

10 H.-D. Schumann, Chem. Fibers Int., 2000, 50, 340.

11 R. Dersch, M. Graeser, A. Greiner and J. H. Wendorff, Aust. J. Chem., 2007, 60, 719; Z.-M. Huang, Y.-Z. Zhang, M. Kotaki and S. Ramakrishna, Compos. Sci. Technol., 2003, 63, 2223; A. Greiner and J. H. Wendorff, Angew. Chem., Int. Ed., 2007, 46, 5670.

12 For example see: R. G. Weiss and P. Terech, Molecular Gels, Springer, Dordrecht, Netherlands, 2006; L. C. Palmer and S. I. Stupp, Acc. Chem. Res., 2008, 41, 1674; C. C. Lee, C. Grenier, E. W. Meijer and A. P. H. Schenning, Chem. Soc. Rev., 2009, 38, 671; B. Xu, Langmuir, 2009, 25, 8375; A. Thierry, C. Straupé, B. Lotz and J. C. Wittmann, Polym. Commun., 1990, 31, 299; T. Shimizu, Advances in Polymer Science 219: Self-assembled Nanomaterials I (Nanofibers), Springer, Berlin, Germany, 2008; M. de Loos, B. L. Feringa and J. H. van Esch, Eur. J. Org. Chem., 2005, 3615; L. Bouteiller, in Advances in Polymer Science 207: Hydrogen Bonded Polymers, ed. W. Binder, Springer, Berlin, Germany, 2007, ch. 2; N. Mohmeyer and H.-W. Schmidt, Chem.Eur. J., 2007, 13, 4499.

13 J. Ding, Y.-L. Hsiao, C. P. Lenges, Y. Niu, S. Reinartz, C. M. Stancik and J. J. Van Gorp, US Pat., 20070125700A1; E. J. Acosta, A. Raghavanpillai, S. Peng, S. Reinartz and S. Moudgil, US Pat., 20080113573A1, 2007.

14 T. Shimizu, M. Masuda and H. Minamikawa, Chem. Rev., 2005, 105, 1401; T. Shimizu, Advances in Polymer Science 220: Selfassembled Nanomaterials II (Nanotubes), Springer, Berlin, Germany, 2008.

15 N. Feeder and W. Jones, Mol. Cryst. Liq. Cryst., 1992, 211, 111; N. Feeder and W. Jones, Acta Crystallogr., Sect. B: Struct. Sci., 1993, 49, 541; N. Feeder and W. Jones, Mol. Cryst. Liq. Cryst., 1994, 240, 231.

16 K. Rosenlehner, B. Schade, C. Böttcher, C. M. Jäger, T. Clark, F. W. Heinemann and A. Hirsch, Chem.-Eur. J., 2010, 16, 9544; C. M. Jäger, A. Hirsch, B. Schade, K. Ludwig, C. Böttcher and T. Clark, Langmuir, 2010, 26, 10460. 